\title{
Proposta de modelo de sistema de registros de população de animais domésticos: comparação entre normas jurídicas brasileira e estrangeiras
}

Proposal of a model of system of identification for domestic animals: a comparison between brazilian and international laws

Propuesta de modelo del sistema de registros de población de animales domésticos: comparación entre las normas legales brasileñas y extranjeras

Nicolau Cardoso Neto ${ }^{1}$

Sheila Olwen Rimes ${ }^{2}$

Ruben Soberón ${ }^{3}$

RESUMO: A relação entre o ser humano e os animais de estimação, como cães e gatos vem tomando proporções gigantescas, podemos ver nos dados publicados pelo censo realizado pelo IBGE, de onde é possível verifica que existe um crescimento maior da população de animais domésticos do que de natalidade de crianças (IBGE, 2015). Análise da base jurídica federal sobre sistema de registros de população de animais domésticos existentes no Brasil e comparar com normas jurídicas estrangeiras que possam servir de referência, como Canadá, Estados Unidos da América, Irlanda e Reino Unido. Esse crescimento acelerado proporciona a identificação de problemas de diversas naturezas e dimensões em centros urbanos, principalmente quanto ao controle de zoonoses e conflitos provenientes da guarda negligente, o que acaba proporcionando um problema de saúde pública. A intenção foi verificar a possibilidade de adequar a realidade brasileira, buscando criar para o Brasil um modelo de sistema de registros de população de animais domésticos. Para tanto, o artigo abordou sobre temas relacionados a guarda responsável, bem-estar animal e modelos de cadastramento que já são aplicados com êxito nos países citados, procurando estruturar um modelo para ser utilizado no Brasil. Ao final, o artigo apresente uma proposta de modelo sistema de registros de população de animais domésticos.

Palavras-chave: Sistema de Registros. Animais Domésticos. Normas Jurídicas. Zoonoses. Saúde Pública.

ABSTRACT: The relationship between humans and pets, especially dogs and cats is taking gigantic proportions, this can be seen by the data recently published by IBGE, where it was verified that the number of pets grows more than the number of child birth (IBGE, 2015). As so foreseen, the purpose of this study is to acknowledge which is the federal juridical basis related to the registration of Domestic Animals in Brazil, comparing them with

\footnotetext{
${ }^{1}$ Professor da Fundação Universidade de Blumenau - FURB, Departamento de Medicina Veterinária. nicolau@scambiental.com.br

2 Universidade Regional de Blumenau - FURB -shiu_or@yahoo.com.br

3 Graduando em Medicina Veterinária - FURB - rubensoberon@yahoo.com.br
} 
the international legal standards that can be of reference, such as Canada, United States of America, Republic of Ireland and United Kingdom. This increase in pet population shows problems of many dimensions that relate to several causes in urban centers, especially when referring to zoonosis and conflicts that come from irresponsible ownership, bringing up a public health issue. The intension was to verify the possibility to adequate them to the reality encountered in Brazil, creating a model of identification for the Domestic Animals in urban areas in this country. As for that, the article addresses themes related to responsible ownership, animal welfare and models of registration already accomplished in the mentioned countries. At the end the article presents the proposal of a model for a system of identification of the Domestic Animals.

Keywords: Registries. Domestic Animals. Enacted Statutes. Zoonoses. Public Health.

RESUMEN: La relación entre los humanos y los animales domésticos, especialmente perros y gatos está tomando proporciones gigantescas, esto se puede ver por los datos recientemente publicados por el IBGE, donde se verificó que el número de animales de compañía crece más que el número de nacimientos de niños (IBGE, 2015). Como por lo previsto, el propósito de este estudio es reconocer que es la base jurídica federal relacionada con el registro de la población de Animales Domésticos en Brasil, comparándolos con los estándares legales internacionales que pueden ser de referencia, tales como Canadá, Estados Unidos de América, República de Irlanda y Reino Unido. Este aumento de la población de mascotas muestra problemas de muchas dimensiones que se relacionan con varias causas en los centros urbanos, especialmente cuando se refiere a la zoonosis y los conflictos que provienen de la propiedad irresponsable, que crían a un problema de salud pública. La intención fue verificar la posibilidad de adecuarlas a la realidad encontrada en Brasil, la creación de un modelo de identificación para la población de Animales Domésticos en las zonas urbanas de este país. En cuanto a eso, el artículo se tratan temas relacionados con la tenencia responsable, el bienestar animal y los modelos de registro ya realizados en los países mencionados. Al final del artículo se presenta la propuesta de un modelo para un sistema de identificación de la población de Animales Domésticos.

Palabras Ilave: Sistema de Registros. Animales Domésticos. Normas Jurídicas. Zoonosis. Salud Pública.

\section{Introdução}

A ligação entre homem e cães é identificada a mais de 27 mil anos, quando lobos começaram a se aproximar de tribos para se alimentar de restos de comida oferecidos pelos homens (1). Nos dias de hoje, o homem vem permitindo a relação entre espécies ao permitir que cães procriem indiscriminadamente, levando ao abandono desses animais que acabam trazendo perigo para a saúde, tanto dos humanos quanto dos animais. 
A fim de analisar esta realidade atual, a Organização Mundial de Saúde - OMS e a World Society for the Protection of Animals - WSPA reuniram cientistas, profissionais de controle animal e líderes de proteção animal para discutir problemas causados pela superpopulação de cães, bem como providenciar ações sugeridas. Para uma padronização de recomendações foi escrito o Guia Para Controle Populacional de Cães (2).

Com o passar do tempo, vem aumentando o número de regulamentações sobre guarda responsável de animais de estimação, tanto em relação ao tratamento dos animais, como, quanto as ações direcionadas a prevenir problemas de saúde que os animais possam vir a causar.

Mas, devemos considerar o sentimento do ser humano em relação aos animais, que, por muitas vezes se compara a compaixão de um ser humano em relação a outro ser humano, levando, muitas vezes, a reações de repulsa contra regulamentações sobre controle animal, pois se acredita erroneamente que essas regulamentações são contra os direitos destes. Mas a maioria destas regulamentações é direcionada às pessoas que deixam de cumprir suas responsabilidades em relação aos cães, supervisionando-os para que não criem problemas para a comunidade onde vivem, em vez de garantir direitos reais aos animais (3).

Por este motivo, o cadastro de animais domésticos de estimação é de extrema importância para o controle populacional deste seguimento que cresce a cada dia. Segundo a Associação Brasileira da Indústria de Produtos para Animais de Estimação ABINPET o mercado Brasileiro deste setor deve crescer $8,2 \%$, estimando um faturamento de $R \$ 16,4$ bilhões em 2014 , sendo que as classes sociais que estão em mais evidência são as classes C e D (4).

Um aspecto importante a ser destacado quanto aos animais são as zoonoses, que são patologias comuns entre animais e humanos, onde ambos fazem papel de hospedeiros ou reservatório, consequentemente, sem o controle populacional destes animais e sem cadastramentos, as chances de manutenção de algumas patologias se multiplicam, trazendo transtornos à população.

Assim, o cadastramento do animal de estimação auxilia, não apenas na recuperação de um animal que fugiu de casa, mas também no bem-estar deste animal de maneira geral, pois através desta é possível identificar o proprietário, responsabilizando-o por eventuais omissões. Chama a atenção para a saúde pública, o fato do abandono de 
animais que aumenta a cada ano, em razão do crescimento da população, especialmente em época de férias (5).

A fim de controlar este problema, a Organização Mundial para Saúde Animal - OIE indicou as seguintes medidas para o manejo populacional canino: educação e legislação para a guarda responsável, registro e identificação dos animais, controle reprodutivo, recolhimento e manejo de cães de rua capturados, controle das fontes de alimento e abrigo, restrição do movimento, educação para a redução dos ataques e mordeduras e eutanásia. Sendo ainda apontados elementos a serem monitorados, como o tamanho populacional, a prevalência de doenças e o nível de guarda responsável (6).

O cadastramento de animais é de fundamental importância para que se possa aplicar responsabilidade em relação aos mesmos. Sem contar que o levantamento da população animal pode estar diretamente relacionado ao ser humano, pois pode trazer benefícios levando em consideração que esses animais necessitam de alimentos, higienização, vacinas e cuidados com a saúde em geral. Também pode ser utilizado para verificar os locais de ataque considerando as zoonoses que podem estar relacionadas ao convívio com animais de estimação. Outro motivo considerável seria o controle populacional (7).

Diante deste contexto, este estudo tem como objetivo a necessidade de definir uma premissa, qual seja, um modelo único para o cadastramento da população animal em zonas urbanas, especialmente para cães e gatos.

\section{Metodologia}

Foi realizado mapeamento da legislação Federal e de algumas normas internacionais, que foram utilizadas como modelo de cadastramento. Foram utilizadas as leis da Ville de Verdun no Canadá, da cidade de Henderson nos Estados Unidos da América, da Irlanda e do Reino Unido, países que já cadastram animais de estimação, com os quais se obteve facilidade de contato com autoridades e residentes para troca de informações.

Esta pesquisa foi realizada por meio de revisão de literatura, análise e comparação da legislação internacional sobre cadastramento, controle populacional e bem-estar animal com a legislação federal sobre sistema de registros de população de animais domésticos vigente no Brasil. 
Primeiramente foi elaborada uma revisão de literatura que aborda os problemas oriundos do abandono de cães e gatos e a importância da guarda responsável. Posterior, houve o mapeamento da legislação federal, objeto do estudo, com o foco em proteção, bem-estar e cadastramento animal de cães e gatos. No mapeamento internacional foram utilizados modelos de cadastramento baseados em leis da Ville de Verdun no Canadá, da cidade de Henderson nos Estados Unidos da América, da Irlanda e do Reino Unido.

Posteriormente ao mapeamento foram analisados os modelos de cadastramento de animais de estimação aplicados nos locais analisados. Ao final foi sugerido uma proposta de modelo de cadastramento com formulário desenvolvido pelos autores.

\section{Discussão}

Os problemas verificados pelo abandono de cães e gatos são associados à segurança e saúde pública. Animais vagando sem controle estão propensos a desenvolver e transmitir doenças, tanto zoonoses para humanos como para os animais. Muitos se tornam agressivos por medo, causando acidentes e ferimentos como mordidas, ocorrem ainda problemas relacionados a barulho e sujidades, também sendo problema os acidentes de trânsito (2).

Para tanto, é considerado maus-tratos a ação de abandono, envenenamento, animais presos constantemente em correntes ou cordas muito curtas, manutenção em lugar antihigiênico, mutilação, presos em espaço incompatível ao porte do animal ou em local sem iluminação e ventilação, utilização em shows que possam thes causar lesão, pânico ou estresse, agressão física, exposição a esforço excessivo e animais debilitados (tração), rinhas (8).

Para a OMS (9), cães e gatos quando não adequadamente tratados, vacinados e vermifugados podem ser uma ameaça para a saúde pública, pois podem transmitir doenças ao ser humano, conhecidas como zoonoses. As principais zoonoses são a raiva, a leptospirose, bicho geográfico e leishmaniose, que podem causar a morte. Além disso, podem contribuir para a disseminação de pulgas, sarna e carrapatos. Outra advertência seria a probabilidade de contaminação ambiental, acidentes de trânsito e agressões que envolvem seres humanos. 
Segundo a OMS (10), as zoonoses são doenças e infecções que podem ser transmitidas para os seres humanos através dos animais de forma natural. Essas doenças são transmitidas por meios diferenciados (água, ar, alimentos, picadas de insetos, dentre outros).

Ao analisar o Boletim Eletrônico Epidemiológico (11), intitulado "Situação Epidemiológica das Zoonoses de Interesse para a Saúde Pública", este informa que as zoonoses apresentam $75 \%$ das doenças infecciosas emergentes no mundo, mostrando um grande problema para saúde pública. Sendo que as ocorrências de notificação zoonótica representam $40 \%$ dos casos importantes para a saúde pública registrados no período de 03/2006 a 02/2010. Esses dados mostram que há necessidade de um controle populacional de animais domésticos e/ou domesticados nas áreas urbanas. Expressando o fato de as zoonoses serem de significativa importância para a saúde pública, principalmente aquelas que ocorrem em áreas urbanas, onde destacam-se o caos de brucelose, leptospirose, raiva e toxoplasmose.

Segundo Dreer (12), das 175 amostras coletadas de cães errantes oriundos de um abrigo da cidade de Umuarama-PR, 20\% resultou em Leptospirose, 37,72\% para borreliose de Lyme, 2.85\% para brucelose e 70,85\% para toxoplasmose. Este estudo comprova que cães errantes são potencias reservatórios de diferentes zoonoses, que contribuem para a manutenção do agente etiológico, na distribuição no meio ambiente e possíveis transmissores de diversas enfermidades para o homem. De forma que algumas medidas preventivas seriam a castração e a realização de campanhas de posse responsável, além da prática de campanhas de adoção, medidas estas consideradas como essenciais para a redução deste problema nas cidades.

Já o conceito de guarda responsável consiste na aceitação e comprometimento do guardião em assumir deveres centrados em atender as necessidades físicas, psicológicas, ambientais do animal e também prevenir os riscos como, uma potencial agressão, transmissão de doenças e quaisquer danos a terceiros (13).

A guarda responsável de animais de companhia configura-se como uma das práticas para promoção do bem-estar animal, sendo de fundamental importância e diretamente relacionada ao papel do Médico Veterinário na sociedade, já que é ele que fornece subsídios para conscientização quanto às necessidades básicas para uma relação 
saudável tanto para os animais, quanto para seus proprietários, independente do senso comum, muitas vezes equivocado (14).

Promover guarda responsável através de legislação e educação é fundamental em um programa de controle populacional de animais de companhia. A colaboração entre as autoridades governamentais locais, Organizações não Governamentais - ONG's, Kennel Clubes, Médicos Veterinários e Conselhos Regionais de Medicina Veterinária - CRMV são importantes para a manutenção dos programas de guarda.

De acordo com Canatto et al. (15), em estudo realizado na cidade de São Paulo que mostra que a guarda de cães e gatos, está associada a fatores culturais, sendo a caracterização da população de animais a base da estruturação adequada de programas de controle populacional e de zoonoses.

Para reforçar, a Declaração Universal dos Direito dos Animais, proclamada pela UNESCO em 1978 (16), em sessão realizada em Bruxelas na Bélgica, preza pelo respeito aos direitos dos animais. Em seu Art. $6^{\circ}$ proclama que "todo o animal que o homem escolheu para ser seu companheiro tem direito a uma duração de vida conforme a sua longevidade natural", e, ainda, "o abandono de um animal é um ato cruel e degradante". Já no Art. 12, assegura que "todo o ato que implique a morte de um grande número de animais é um genocídio", isto é, um crime contra a espécie. No Art.14 afirma que "os direitos do animal devem ser defendidos pela lei, assim como os direitos dos homens".

Assim, é possível afirmar que o nível básico de bem-estar está relacionado aos cuidados mínimos que devem ser oferecidos aos animais, com base na legislação existente referente à guarda responsável e ao controle animal, que deve prover alimento, água, abrigo e tratamento de doenças e outras injúrias (7).

Um marco para o pensamento sobre os direitos dos animais no Brasil, foi a Constituição Federal de 1988, que proibiu em âmbito constitucional que o animal nãohumano seja tratado de forma cruel, passando a reconhecer a este o direito de ser respeitado em seu valor intrínseco, em sua integridade, sua vida e sua liberdade (17).

Rebate, a conotação histórica de que os animais sempre foram considerados como propriedade e que não tinham direitos. A Suprema Corte dos Estados Unidos da América vem reconhecendo que animais de estimação são mais que meras propriedades, pois são seres vivos que possuem sentimentos, mostram emoções e afeição, sendo assim mais que simples objetos (18). 
Percebe-se assim, que o direito dos animais varia significativamente de país para país, não existindo assim intervenções que funcionem para todas as situações em seis diferentes contextos legais e culturais. O conceito de universal do guia humanitário de manejo de população canina se dá pelo fato da compreensão de que é necessário focar nas causas do abandono e não apenas nos sintomas (16). O que reforça a necessidade da realização de um cadastramento para se compreender as necessidades e peculiaridades do tema, assim, passamos a analisar normas federais Brasileiras sobre o tema, além de exemplos internacionais.

\section{Resultados}

De uma análise das normas federais sobre o tema, destacam-se a Lei de Crimes Ambientais (9.605/98) (8), o Decreto Federal que regulamenta a Lei de Crimes Ambientais (6.514/08) (19), a Resolução do Conselho Nacional do Meio Ambiente - CONAMA 394/07 (20) e a Instrução Normativa IBAMA 10/11 (21).

O CONAMA, em sua resolução 394/07 estabelece os critérios para determinação de espécies silvestres a serem criadas e comercializadas como animais de estimação (20). Posteriormente a criação desta Resolução, o Instituto Brasileiro do Meio Ambiente e dos Recursos Naturais Renováveis - IBAMA criou um sistema para cadastro, específico para passeriformes, que procura realizar o controle e o monitoramento e foi intitulado como SISPASS - Sistema Informatizado de Passeriformes.

Segundo a Normativa 10/11 do IBAMA, para poder criar aves, o requerente, deve ter no mínimo 18 anos, não pode ser culpado em processo administrativo ou judicial, em andamento, julgado ou cumprindo, nos termos do inciso X, do Art. $3^{\circ}$ do Decreto 6.514/08 ou no inciso XI do Art. 72 da Lei 9.605/98. Deve, ainda, mandar ao IBAMA seus documentos autenticados e um comprovante de residência com vencimento não superior a 60 dias, ter um limite máximo estabelecido de aves que pode comportar seu plantel e sempre que alterar dados cadastrais ou endereço o requerente (criador), deve atualizar os dados no sistema num prazo máximo de 7 dias, e enviar novamente seus documentos autenticados e o comprovante de residência para o IBAMA, no prazo de trinta dias (21).

Através da pesquisa realizada, os autores deste estudo, não encontraram dados referentes a um outro sistema informatizado, que seja similar ao utilizado pelo IBAMA 
(SISPASS) para a criação, comercialização e guarda responsável de animais de companhia (cães e gatos) em âmbito Federal, por esta razão citou o único documento federal que procura realizar este tipo de controle e por isso poderá servir de referência para a criação de cadastramento futuro para animais de companhia.

Para facilitar a leitura das normas analisadas, foi realizado mapeamento legal, técnica metodológica de pesquisa em Leis sobre assuntos determinados. Para tanto, a Tabela 01 apresenta a identificação das normas federais que podem ter relação com um modelo de sistema de registros de população de animais domésticos e daquelas similares que poderão ser utilizadas como referência para a prática do tema abordado nesta pesquisa.

Tabela 01. Mapeamento das leis federais, relacionadas ao cadastramento da população de animais de companhia.

\begin{tabular}{|c|c|c|c|c|}
\hline Norma & Artigo(s) & Assunto & & O que dispõe \\
\hline $\begin{array}{l}\text { Constituição } \\
\text { Federal } 1988\end{array}$ & $\begin{array}{l}\text { Art. 225, } \\
\text { Inciso } \\
\text { VII do } \\
\$ 1^{\circ}\end{array}$ & $\begin{array}{l}\text { Direito } \\
\text { meio } \\
\text { ambiente } \\
\text { dever } \\
\text { defender } \\
\text { preservar. }\end{array}$ & $\begin{array}{r}\mathrm{e} \\
\mathrm{de} \\
\mathrm{e}\end{array}$ & $\begin{array}{l}\text { Para assegurar a efetividade desse direito: ao meio ambiente } \\
\text { ecologicamente equilibrado, bem de uso comum do povo e } \\
\text { essencial à sadia qualidade de vida, impondo-se ao Poder } \\
\text { Público e à coletividade o dever de defendê-lo e preservá-lo para } \\
\text { as presentes e futuras gerações, incumbe ao Poder Público: } \\
\text { - Proteger a fauna e a flora, vedadas, na forma da lei, as práticas } \\
\text { que coloquem em risco sua função ecológica, provoquem a } \\
\text { extinção de espécies ou submetam os animais a crueldade. }\end{array}$ \\
\hline
\end{tabular}

\begin{tabular}{|c|c|c|c|}
\hline $9605 / 1998$ & $\S 2^{\circ}$ & maus- tratos. & $\begin{array}{l}\text { - A pena é aumentada de um sexto a um terço, se ocorre morte } \\
\text { do animal. }\end{array}$ \\
\hline $\begin{array}{l}\text { Decreto } \\
6514 / 08\end{array}$ & Art. 29 & $\begin{array}{l}\text { Especificação } \\
\text { das sanções } \\
\text { aplicáveis. }\end{array}$ & $\begin{array}{l}\text { Praticar ato de abuso, maus-tratos, ferir ou mutilar animais } \\
\text { silvestres, domésticos ou domesticados, nativos ou exóticos: } \\
\text { Multa de } R \$ 500,00 \text { (quinhentos reais) a } R \$ 3.000,00 \text { (três mil } \\
\text { reais) por indivíduo. }\end{array}$ \\
\hline $\begin{array}{l}\text { Resolução } \\
\text { CONAMA } \\
394 / 2007\end{array}$ & Art. $1^{\circ}$ & $\begin{array}{l}\text { Critério na } \\
\text { determinação } \\
\text { das espécies. }\end{array}$ & $\begin{array}{l}\text { Estabelece os critérios na determinação das espécies da fauna } \\
\text { silvestre, cuja criação e comercialização poderá ser permitida } \\
\text { como animais de estimação. }\end{array}$ \\
\hline $\begin{array}{l}\text { Resolução } \\
\text { CONAMA } \\
394 / 2007\end{array}$ & Art. $6^{\circ}$ & $\begin{array}{l}\text { Sistema } \\
\text { informatizado. }\end{array}$ & $\begin{array}{l}\text { O IBAMA disponibilizará um sistema informatizado de fauna ex } \\
\text { situ para controle, monitoramento e rastreabilidade de animais de } \\
\text { criadouros, estabelecimentos comerciais e compradores. }\end{array}$ \\
\hline $\begin{array}{l}\text { Instrução } \\
\text { Normativa } \\
10 / 2011\end{array}$ & Art. $3^{\circ}$ & $\begin{array}{l}\text { Validade da } \\
\text { autorização } \\
\text { de criação de } \\
\text { passeriformes }\end{array}$ & $\begin{array}{l}\text { A autorização para Criação Amadora Passeriformes tem validade } \\
\text { anual, sempre no período de } 01 \text { de agosto a } 31 \text { de julho, devendo } \\
\text { ser requerida nova licença } 30 \text { (trinta) dias antes da data de } \\
\text { vencimento. }\end{array}$ \\
\hline
\end{tabular}

Instrução $\quad$ Art. $4^{\circ}$, Solicitação de - A solicitação de inclusão na categoria de Criador Amador de Normativa $\S^{\circ}, \S^{\circ}$ inclusão ou Passeriformes somente poderá ser feita por maiores de dezoito 10/2011 e incisos alteração de anos;

I, II e III, cadastro. - O interessado não poderá ter sido considerado culpado, em $\S 6^{\circ} \quad$ processo administrativo ou judicial transitado em julgado, cuja punição ainda esteja cumprindo, nos termos do inciso $X$ do Artigo $3^{\circ}$ do Decreto $n^{\circ} 6.514$, de 22 de julho de 2008 ou no inciso XI do 


\begin{abstract}
Artigo 72 da Lei 9.605/1998;
- Para homologação do cadastro e liberação, o interessado deverá, após realizar a solicitação, apresentar ao Órgão Federal de sua jurisdição cópia autenticada dos seguintes documentos:

I - Documento oficial de Identificação com foto;

II - CPF;

III - Comprovante de residência expedido nos últimos 60 dias;

- Sempre que os dados cadastrais forem alterados, principalmente o endereço do estabelecimento, deverá atualizar seus dados cadastrais no sistema no prazo de 07 (sete) dias e encaminhar ao IBAMA, dentro no prazo de 30 dias, os documentos listados nos incisos I a III, para homologação dos novos dados.
\end{abstract}

Fonte: Elaborada pelos autores.

Para a confecção do modelo de sistema de registros de população de animais domésticos, além da análise das referidas leis, foram utilizados modelos de cadastramento baseados em leis internacionais, como as das cidades de Verdun no Canadá e Henderson nos Estados Unidos da América, além das leis da República da Irlanda e do Reino Unido. A ideia foi analisar o modelo de cadastramento criado por estes. O ICAM (Internacional Companion Animal Management Coalition) motiva que seja buscado em outros países ações que estão sendo aplicadas e que mostrem um resultado positivo como proposta de referência para a criação de normas próprias.

Da pesquisa, foi possível perceber que a República da Irlanda implantou a obrigatoriedade do microchip no ano de 2015, e a Inglaterra está em fase de educação da população para a implantação desta obrigatoriedade a partir de 2016. A educação se dá por meios de mídia, fazendo com que toda população tenha acesso e conheça a necessidade e aplicabilidade das leis.

O valor do licenciamento para animais esterilizados deve ser menor do que o valor para animais não esterilizados, assim incentivando o procedimento cirúrgico de esterilização e evitando que os animais se reproduzam de forma descontrolada gerando abandono, problemas de saúde pública ou zoonose. Os valores arrecadados podem ser utilizados para ações relacionadas ao bem-estar animal e programas de proteção animal.

Para ter sucesso na aplicação das leis é necessário estipular e deixar claro qual órgão será responsável pela aplicação das penalidades, visto que para muitas ações, é necessário ter poder de polícia para serem realizadas. 
É muito importante dar ênfase à educação, através dela pode-se conscientizar as pessoas sobre posse responsável, bem como a importância do cadastramento, deixando claro as penalidades sofridas quando não se toma para si a responsabilidade.

O modelo de cadastramento da cidade de Verdun foi escolhido pelo contato existente com uma habitante da cidade que possui animal de estimação, que facilitou a pesquisa do modelo existente. Verdun é uma vila de Montreal na Província de Quebec no Canadá. Na data de 03 de maio de 2011, foi criado pelo conselho municipal a Carta sobre conduta adequada aos proprietários de animais de estimação, no intuito de fazer respeitar-se a vida desses pets (22).

A Ville de Verdun faz controle do número de cães e gatos não castrados, limitando-se a um por residência, sendo obrigatório registrar filhotes com mais de 90 dias. Deve-se fazer o registro dentro de 15 dias da aquisição de um animal de estimação ou no dia seguinte há completar 3 meses. Além do microchip, cães e gatos devem utilizar o tag de identificação expedido pelo distrito. Os formulários para registro estão disponíveis no sítio eletrônico, sendo que o site em inglês está em manutenção e traz apenas informações referentes ao ano de 2012, mas pode-se encontrar os formulários atualizados no sítio eletrônico em francês (22).

Após imprimir e preencher os formulários, o cidadão dirige-se ao escritório físico. Os proprietários de pet já cadastrados recebem uma correspondência anual, lembrando que está na hora de renovar o registro de seu animal, eles têm a opção de levar os formulários preenchidos pessoalmente até o escritório ou retornar por correio no envelope que recebem junto com os formulários (22).

Todas as informações estão disponíveis no sítio eletrônico de Verdum, onde estão disponíveis os formulários necessários para registro dos animais de estimação. O site está disponível em francês e inglês, facilitando acesso a toda comunidade (22).

Caso seja a primeira vez que estejam fazendo o cadastro, pode ser utilizado o site para baixar e imprimir os formulários em PDF, nos anos seguintes os documentos serão enviados pelo correio. No caso de alteração em alguma informação relacionada ao animal, existe formulário específico, também disponível no site, para informar esses dados, como óbito, mudança de propriedade e mudança de endereço (22).

O modelo de cadastramento da cidade de Henderson foi escolhido por ter um estatuto comprometido a trabalhar junto à comunidade para reduzir o sofrimento e estresse 
animal, facilitar o retorno seguro de animais perdidos a suas famílias e garante um ambiente seguro, confortável para animais perdidos ou abandonados. Além de prestar serviços de adoção, educar a população sobre guarda responsável, fazer cumprir as leis relacionadas a controle animal e ser a autoridade de controle antirrábico.

Os Estados Unidos da América - EUA é dividido em 50 Estados, sendo as leis aplicadas pela polícia e departamentos locais. A cidade de Henderson localiza-se no estado de Nevada, Estados Unidos da América e a Organização de Controle e Bem-Estar Animal de Henderson existe para servir a comunidade, dar assistência, conforto e atendimento médico para animais sob os cuidados do abrigo e fazer aplicar-se a lei que protege animais e comunidade (23).

O Estatuto da Cidade de Henderson requer que cães e gatos com quatro meses ou mais sejam esterilizados, exceto quando se tratar de circunstâncias específicas (23). Todos os proprietários de animais de estimação residindo em Henderson, tem 120 dias para cumprir com esta portaria que passou pela câmara municipal em 3 de agosto de 2010.

Todas as informações e leis sobre controle, bem-estar e adoção de animais, assim como os formulários para obter a licença estão disponíveis no sitio eletrônico www.cityofhenderson.com. A fiscalização é realizada pelos oficiais de controle animal, que são vinculados ao departamento de polícia de Henderson, fazendo parte da segurança pública, atendendo assuntos referentes a animais de estimação, fazendo aplicar-se a lei (23).

O Reino Unido é composto pelos países: Inglaterra, Escócia, Irlanda do Norte, assim como País de Gales. A República da Irlanda com capital Dublin, não pertence ao Reino Unido.

O governo escocês considera que o fator chave para encorajar posse responsável para cães e bem-estar animal seja a educação. Com essa finalidade publicaram o Código de Conduta para o bem-estar de cães em 2010 (24). Dessa maneira o Governo escocês concorda que a implantação de microchip seja uma forma efetiva de identificação animal e reconhece os benefícios relacionados a ajudar a reunir cães perdidos a seus proprietários.

A secção 5.12 do Code of Practice for the Welfare of Dogs, publicado em março de 2010, recomenda o implante de microchip, deixando que essa decisão seja voluntária por parte de cada cidadão. Um dos principais motivos que levou o sistema de registros a ser 
abolido na década de 1980 foram as despesas com o programa, sendo estes maiores do que a receita. O governo escocês no momento não tem evidências de que a obrigatoriedade da identificação por microchip coibiria maus tratos. Mas estão monitorando os progressos alcançados em outras partes do Reino Unido em relação a implantação de microchips para identificação (24).

O Animal Welfare Act 2006, que entrou em vigor partir de 06/04/2007, é o documento base sobre Bem-Estar Animal na Inglaterra. Essa lei aumentou e introduziu novas penalidades para combater atos de crueldade, negligência, mutilação, corte de cauda, briga de animais e animais utilizados como premiação. Este documento, obrigou a todos mantenedores/proprietários de animais de estimação a prover cuidados, como ambiente e dieta nutricional adequada, aptidão para demonstrar seus comportamentos naturais, proteção contra dor, sofrimento, ferimento e doença e considerar a necessidade do animal de ser domiciliado com ou separado de outros animais (25).

A cada ano mais de 100.000 cães são abandonados ou perdidos a um custo de $£ 57$ milhões (libras esterlinas) aos pagadores de impostos e caridades de bem-estar animal (Department for Environment Food \& Rural Affairs). A partir de 06 de abril de 2016, o implante de microchip em cães passou a ser obrigatória na Inglaterra (26). Várias autoridades se posicionaram favoráveis a essa nova lei de obrigatoriedade de implantação de microchip.

O modelo de cadastramento adotado pela Irlanda do Norte mostra como existem opções disponíveis para tornar mais fácil para os habitantes cadastrarem seus animais. Todo cão deve ter implantado um microchip antes de ser cadastrado para obtenção de licença. O número de microchip será informado no momento da solicitação de cadastro para obtenção da licença. A solicitação pode ser feita online, havendo a possibilidade de imprimir o formulário e depois entregar no escritório físico. Existe multa para quem não tiver licença para posse de cães. (27).

A República da Irlanda passou a exigir, a partir de junho de 2015, a implantação de microchip em cães, pela S.I. № 63 of 2015. Conforme o Control of Dogs Act 1986, alterado em 1992, onde todo proprietário de cão deve possuir licença. As licenças são adquiridas nas Agências do Correio (tipo individual), Autoridade local (geral e tempo de vida). Tipos de licenças: individual - cobre um cão pelo período de 12 meses (€20); geral - para 
proprietários de canis pelo período de 12 meses (€400); tempo de vida - pelo período de vida do cão ao qual foi emitida a licença (€120) (28).

Diante do revelado, este artigo passa a sugerir uma proposta para o Modelo de sistema de registros de população de animais domésticos sugerido (Quadro 01), se posto em prática, alguns dados terão que ser levantados no município, tais como: população total de cães e gatos; educação contínua em ensino fundamental do terceiro ao quarto ano; educação contínua em conscientização da população sobre guarda responsável; as leis devem ser amplamente divulgadas (rádio, jornal, televisão, internet, outdoor e outros), para a comunidade.

Tendo como base para elaboração da proposta de modelo, usamos o formulário de Verdun Canadá. No formulário são inclusas informações sobre o proprietário/tutor bem como conhecimentos sobre características do animal, sexo, idade, cor, raça. Consta ainda campo para qualquer alteração de informações como, mudança de endereço e propriedade, visto que se não forem realizadas as alterações o antigo proprietário continua responsável pelo animal.

O pagamento de uma taxa de cadastramento e identificação eletrônica se refere a Licença do cadastro animal vigente no ano, para ter um controle anual dos animais cadastrados sendo renovado sempre ao início do ano tendo a validade de um ano, controlando assim os animais que foram imunizados e esterilizados, acompanhados de um laudo emitido por Médico Veterinário devidamente registrado em órgão de classe.

A identificação eletrônica dos animais deve ser feita por meio de microchip, de padrão ISO internacional, assim evita desnecessariamente que o animal tenha que ser novamente microchipado para ser cadastrado em outra localidade. 
Quadro 01. Modelo de sistema de registros de população de animais domésticos.

\begin{tabular}{|c|}
\hline $\begin{array}{l}\text { Dados do Tutor } \\
\text { 0000/Ano }\end{array}$ \\
\hline Nome \\
\hline Endereço (completo): \\
\hline $\begin{array}{l}\text { Telefone residencial } \quad \text { Telefone comercial } \\
\text { e-mail: }\end{array}$ \\
\hline Notas: (mudança de endereço residencial, óbito, doação ou outros) \\
\hline Licença \\
\hline Número da licença ano anterior \\
\hline Número da licença ano corrente \\
\hline Data de emissão da licença \\
\hline Valor da licença \\
\hline Validade da licença: 01 de janeiro a 31 de dezembro (do ano corrente). \\
\hline Dados do animal \\
\hline Nome: \\
\hline Raça: \\
\hline Veterinário responsável: $\mathrm{N}^{\circ}$ do CRMV \\
\hline Sexo: machq fêmea \\
\hline Vacinado (Antirrábica) $\quad$ GS QN Data: \\
\hline $\begin{array}{l}\text { Castrado } \quad \text { G S } \quad \text { पN Data: } \\
\text { Se o cão for esterilizado, incluir documento que comprove a esterilização. }\end{array}$ \\
\hline Data de Nascimento/Idade aproximada: \\
\hline Número do microchip: \\
\hline Outras marcas importantes/diferenciais. \\
\hline $\begin{array}{l}\text { Origem do animal } \square \text { adoçãa } \square \text { criador } \square \text { individual } \square \text { outra } \\
\text { Outra qual: }\end{array}$ \\
\hline
\end{tabular}

\section{Considerações finais}

A relação entre o ser humano e os animais de estimação, como cães e gatos vem tomando proporções gigantescas, podemos ver nos dados publicados pelo censo realizado pelo IBGE, de onde é possível verificar que existe um crescimento maior da população de animais domésticos do que de natalidade de crianças (29).

As leis referentes ao cadastramento e identificação animal de países como Canadá, Estados Unidos da América, Reino Unido e República da Irlanda foram estudadas, havendo assim a possibilidade de realizar uma comparação de alguns dos sistemas de registros de população de animais domésticos estrangeiros com o sistema legal existente no Brasil. Foi então verificada a possibilidade de construir um modelo sistema de registros 
de população de animais domésticos, com a finalidade de promover a Saúde Pública, combatendo zoonoses, mostrando que a legislação nacional e local permite que isso seja realizado, sendo assim foi elaborado um modelo empregando referências legais identificadas utilizando para isso formulários de licenciamento existentes em países que já executam este tipo de controle.

Ao final da pesquisa é possível afirmar que é possível construir um sistema de registros de população de animais domésticos, já que o estudo realizado confirmou ser admissível adequar e implementar as leis de posse responsável e controle populacional de cães e gatos baseado em leis Brasileiras. Devendo, para tanto, definir uma premissa, qual seja, um modelo único para o sistema de registros de população de animais domésticos, especialmente para cães e gatos, em todo o país.

Esta premissa de haver um único modelo de sistema, pretende possibilitar a aplicação em cada um dos municípios do Brasil, de um formulário único, de forma a possibilitar a troca de informações e até mesmo a adequação em havendo alteração da residência do animal entre municípios ou entre estados.

Assim é possível confeccionar um modelo de sistema utilizando referencias legais identificadas no Brasil e também de países que já executam este tipo de controle, como foi demonstrado por meio desta pesquisa.

Este estudo deixa as seguintes sugestões quanto ao tema: seria interessante aplicar o modelo em um município, de forma, que este possa ser implementado e devidamente testado, já que a necessidade de eventuais alterações pode surgir. Para tanto será necessário criar modelo de projeto de lei para a implementação legislativa municipal, objeto este que pode ser tema de um novo trabalho.

\section{Referências}

1. Skoglund P, Ersmark E, Palkopoulou E, Dalén L. Ancient wolf genome reveals an early divergence of domestic dog ancestors and admixture into high-latitude breeds. Current Biology, (2015 im press).

2. International Companion Animal Management Coalition - ICAM. Humane dog population management guidance. 2007. Disponível em: <http://www.ifaw.org/sites/default/files/ICAMHumanecatpopulation.pdf>. Acesso em: 15 out. 2015. 
3. Beck, Alan M., The Ecology of Stray Dogs: A Study of Free-Ranging Urban Animals (1973). Purdue University Press e-books. Book 3. Disponível em:

<http://docs.lib.purdue.edu/purduepress_ebooks/3>. Acesso em: 14 nov. 2015.

4. Abinpet. Brasil está entre as principais forças motrizes do mercado pet mundial, ressalta Abinpet. São Paulo, 21 out. 2014. Disponível em: <http://abinpet.org.br/sem-categoria/brasil-esta-entreas-principais-forcas-motrizes-do-mercado-pet-mundial-ressalta-abinpet/>. Acesso em: 02 nov. 2014.

5. Silva, Carlos Flávio B. da. A Medicina Veterinária e o Dia Mundial da Saúde. 2011. Disponível em: <http://www.crmvrs.gov.br/456art.pdf>. Acesso em: 25 set. 2015.

6. World Organization for Animal Health. Stray dog population control. Terrestril Animal Health Code. Paris: OIE; 2010. Disponível em:

<http://web.oie.int/eng/normes/mcode/a_summry.htm>. Acesso em: 30 nov. 2015.

7. Garcia, Rita de Cassia Maria; Calderon, Néstor; Ferreira, Fernando. Consolidação de diretrizes internacionais de manejo de populações caninas em áreas urbanas e proposta de indicadores para seu gerenciamento. Rev Panam Salud

Publica, Washington, v.32, n.2, Aug. 2012. Disponível em:

$<$ http://www.scielosp.org/scielo.php?script=sci_arttext\&pid=S102049892012000800008\&ln $\mathrm{g}=\mathrm{en} \& \mathrm{nrm}=$ iso $>$. Acesso em: 30 nov 2015.

8. BRASIL. Lei n. 9605, de 12 de fevereiro de 1998. Dispõe sobre as sanções penais e administrativas derivadas de condutas e atividades lesivas ao meio ambiente, e dá outras providências. Disponível em: <http://www.planalto.gov.br/ccivil_03/LEIS/L9605.htm>. Acesso em: 15 set. 2015.

9. World Health Organization - WHO. Expert comitee on rabies. 8. Ed. Switzerlan: WHO, 2005. 99 p. (Thechnical report series).

10. World Health Organization- WHO. Zoonoses, 20015. Disponível em: <http://www.who.int/topics/zoonoses/en/>. Acessado em: 30 fev. 2016.

11. Ministério da Saúde. Situação epidemiológica das zoonoses de interesse para a saúde pública. Boletim Eletrônico Epidemiológico, Ano 10, n. 2, 2010. Disponível em: www.saude.gov.br/svs Acesso em: 2 set. 2015.

12. Dreer, Márcia Küster de Paula. Leptospirose, borreliose de Lyme, brucelose e toxoplasmose em cães errantes albergados em um abrigo da cidade de Umuarama, Paraná, Brasil. 2012. Disponível em: <http://seshat.unipar.br/trabalho/leptospiroseborreliose-de-lyme-brucelose-e-toxoplasmose-em-caes-errantes-albergados-em-umabrigo-da/>. Acesso em: 11 out. 2015.

13. Santana, L. R.; Oliveira, T. P. Guarda responsável e dignidade dos animais. In: Congresso Internacional de Direito Ambiental, 2004, São Paulo. Anais. 
14. Silvano, D. et al. Divulgação dos princípios da guarda responsável: uma vertente possível no trabalho de pesquisa a campo. Revista Eletrônica Novo Enfoque, v. 9, n. 9, p. 64- 86, 2010.

15. Canatto, B.D. et al. Caracterização demográfica das populações de cães e gatos supervisionados do município de São Paulo. Arq. Bras. Med. Vet. Zootec. Belo Horizonte, v.64, n.6, p.1515-1523. Dec. 2012. Disponível em: <http://www.scielo. br/scielo.php?script=sci_arttext\&pid=S0102-09352012000600017\&lng=en\&nrm=iso >. Acesso em: 30 nov. 2015.

16. WSPA - The world society for the protection of animals. Disponível em: <http://www.wspa-international.org>. Acesso em: 15 ago. 2015.

17. Roso, Luís Roberto. O Direito Constitucional e a Efetividade de suas normas. 5. ed. São Paulo, Saraiva, 2001. p. 159.

18. Kelch, Thomas G.. Toward a non property status for animals. 6 N.Y.U. Envtl. L.J. (1998). p. 537.

19. Brasil. Decreto n. 6514, de 22 de julho de 2008. Dispõe sobre as infrações e sanções administrativas ao meio ambiente, estabelece o processo administrativo federal para apuração destas infrações, e dá outras providências. Disponível em: <http://www.planalto.gov.br/ccivil_03/_ato2007-2010/2008/decreto/D6514.htm>. Acesso em: 15 set. 2015.

20. Conselho Nacional do Meio Ambiente- CONAMA -. Estabelece os critérios para a determinação de espécies silvestres a serem criadas e comercializadas como animais de estimação. Resolução n. 394, de 6 de novembro de 2007. Disponível em: <http://www.mma.gov.br/port/conama/legiabre.cfm?codlegi=542>. Acesso em: 15 set. 2015.

21. Instituto Brasileiro do Meio Ambiente e dos Recursos Naturais Renováveis - IBAMA . Instrução Normativa no 10, de 20 de setembro de 2011. Criação Amadora e Comercial de Passeriformes Nativos. p. 1-38. Disponível em:<https://servicos.ibama.gov.br/phocadownload/legislacao/instrucao_normativa_n_10_d e_20_setembro_2011.pdf>. Acesso em: 15 set. 2015.

22. Verdum. Citizen Services. Disponível em: $<$ http://ville.montreal.qc.ca/portal/page?_pageid=2480,2899219\&_dad=portal\&_schema=P ORTAL>. Acesso em: 11 out. 2015.

23. Henderson. City of Henderson. Animal Control. 2015. Disponível em: <Estados Unidos da América City of Henderson. Animal Control. 2015. Disponível em: Acesso em: 10 out. 2015.>. Acesso em: 11 out. 2015.

24. Escócia. Dog Control and Welfare. Scotish Government. Scotland, 2012. Parliament Copyright. Disponível em: 
$<$ http://www.publications.parliament.uk/pa/cm201213/cmselect/cmenfru/wri e/dogcontrol z/dog73.htm>. Acesso em: 18 out. 2015.

25. Inglaterra. Order no 901, de 19 de março de 1992. The Control Of Dogs Order 1992. London, 01 abr. 1992. Disponível em: <http://www.legislation.gov.uk/uksi/1992/901/made>. Acesso em: 18 out. 2015.

26. Inglaterra. Department for environment food \& rural affairs. All dogs in England to get free microchips. 2013. Disponível em: <https://www.gov.uk/government/news/all-dogs-inengland-to-get-free-microchips>. Acesso em: 10 out. 2015.

27. Belfast City Council. Apply for a dog license. Belfast, 2015. Disponível em: $<$ http://www.belfastcity.gov.uk/buildingcontrolenvironment/dogcontrolanimalwelfare/doglicen ces.aspx>. Acesso em: 18 Out.2015.

28. Irlanda. Statutory Instruments No 63 of 2015. Dublin, 01/06/2015. Disponível em: <http://www.irishstatutebook.ie/eli/2015/si/63/made/en/pdf>. Acesso em: 18 out. 2015.

29. Instituto Brasileiro de Geografia e Estatística - IBGE . Infográficos: dados gerais dos municípios. 2014. Disponível em: <http://cod.ibge.gov.br/23230>. Acesso em: 02 jun. 2015.

Recebido em: 18/9/2016 Aprovado em: 29/9/2016

\section{Como citar este artigo:}

Cardoso Neto, N; Rimes SO, Soberón R. Proposta de modelo de sistema de registros de população de animais domésticos: comparação entre normas jurídicas brasileira e estrangeiras. Revista Cadernos lberoAmericanos de Direito Sanitário. 2016 abr./jun, 5(2):31-49. 